\section{JOGOS COMO TECNOLOGIAS EDUCACIONAIS PARA O ENSINO DE GENÉTICA: A APRENDIZAGEM POR MEIO DO LÚDICO}

Games as educational technology for teaching genetic: learning through the playful

Juegos educativos para el aprendizaje de la genética: a aprendizagem por medio del lúdico

\begin{abstract}
Resumo
A genética é uma das áreas da biologia em que os alunos demonstram maior grau de dificuldade, por ser complexa e trazer conteúdos de difícil assimilação. O presente trabalho teve como objetivo elaborar o jogo intitulado "Jogando com a genética", bem como avaliar a eficácia dessa tecnologia educacional no ensino de genética. $\mathrm{O}$ jogo informatizado de perguntas e respostas acerca dos principais conceitos de genética foi criado em Microsoft Office Power Point, considerando a essência das metodologias lúdicas. A proposta pedagógica foi realizada em uma turma do $3^{\circ}$ ano do Ensino Médio do Centro de Ensino em Período Integral na cidade de Cristalina, Goiás. Os resultados da pesquisa foram analisados por meio de questionários pré-teste e pós-teste e de observações in loco. Verificou-se que os jogos associados ao método tradicional de ensino possibilitam entendimento dos conteúdos, participação e interação dos alunos nas aulas. A pesquisa permitiu caracterizar um novo recurso didático que pode ser reproduzido e usado por outros educadores no ensino de genética.
\end{abstract}

Palavras - Chave: Educação lúdica, Jogos pedagógicos, Tecnologia educacional, Genética, Aprendizagem significativa.

\begin{abstract}
Genetics is an area of biology in which students demonstrate a higher degree of difficulty because it is complex and difficult to assimilate. The present work had as objective to elaborate the game titled "Playing with the genetics", as well as to evaluate the effectiveness of this educational technology in the teaching of genetics. The computerized question and answer game about key genetics concepts was created in Microsoft Office Power Point, considering the essence of playful methodologies. The pedagogical proposal was carried out in a group of the 3rd year of the Secondary School of Centro de Ensino em Período Integral na cidade de Cristalina, Goiás. The results of the research were analyzed through pre-test and post-test questionnaires and in loco observations. It was verified that games associated to the traditional method of teaching make possible the understanding of the contents, participation and interaction of the students in the classes. The research allowed to characterize a new didactic resource that can be reproduced and used by other educators in the teaching of genetics.

Key - Words: Educational Games, Technology Education, Teaching Experience, Learning Activities.
\end{abstract}

\section{Resumen}

Una genética es una área de la biología en la que los estudiantes demuestran mayor grado de dificultad, por ser complejo y trazar contenidos de difícil asimilación. O presente trabajo tuvo como objetivo elaborar el juego intitulado "Jogando con una genética", así como evaluar la eficacia de esta tecnología educativa no ensino de genética. El juego informatizado de preguntas y respuestas acerca de los principales conceptos de genética fue creado en Microsoft Office Power Point, considerando una esencia de las metodologías lúdicas. Una propuesta pedagógica realizada en un período de $3^{0}$ año de la Enseñanza Media Centro de Ensino em Período Integral na cidade de Cristalina, Goiás. Los resultados de la investigación se han analizado por medio de cuestionarios pre-test y post-test y de observaciones in loco. Verificou-se que los juegos se asocian a un método tradicional de enseñanza que posibilitan el entendimiento de los contenidos, la participación y la enseñanza de los alumnos en las aulas. Una investigación permitió caracterizar un nuevo recurso didáctico que puede ser reproducido y usado por otros educadores no ensino de genética.

Palabras clave : Lúdico, Juegos educativos, Tecnología, Ensino de Genética, Aprendizismo.
AUTORAS:

MEIRIDIANE RIBEIRO DA

SILVA $^{1}$

ORCID 0000-0001-5131-8973

${ }^{1}$ Universidade Federal de Goiás (UFG)

ADRIANA MARIA ANTUNES ${ }^{2}$

ORCID 0000-0002-2346-6036

Universidade Federal de Goiás (UFG)

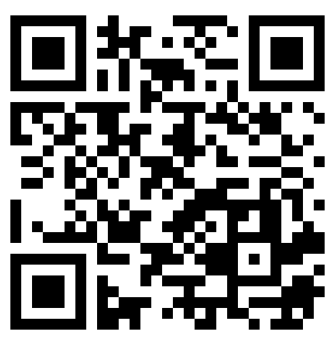

Para citar este artigo:

SILVA, M. R.; ANTUNES, A. M. Jogos como tecnologias educacionais para o ensino de genética: $A$ aprendizagem por meio do lúdico. Revista Eletrônica Ludus Scientiae, Foz do Iguaçu, v. 01, n. 01, p. 175-186, jan./jul. 2017. 


\section{INTRODUÇÃO}

A genética é a ciência que estuda a natureza química do material hereditário e os mecanismos de transferência das informações contidas no ácido desoxirribonucleico (DNA) de uma geração para outra. De acordo com Trivelato (1988) a genética é uma das áreas da biologia de mais difícil compreensão, em função da complexidade dos conteúdos. Segundo esse autor muitas vezes a teoria por si só não é suficiente para o aprendizado, pois não permite que os estudantes entendam de forma clara e coesa o que realmente acontece nos sistemas biológicos. Moreira e Silva (2001) também concordam com a ideia de que a genética é uma das áreas em que há maior dificuldade no desenvolvimento do processo de ensino-aprendizagem, uma vez que exige do aluno conhecimentos prévios em diversas áreas, pois relacionam conceitos com conteúdos ministrados em anos escolares anteriores. Assim, como os conteúdos de genética são considerados complexos e de difícil compreensão, é importante buscar novas formas de ensinar e desenvolver práticas pedagógicas inovadoras que sejam capazes de facilitar o entendimento dos alunos acerca dos conceitos desta disciplina (MASCARENHAS et al 2016).

O papel do professor é mediar e facilitar o ensino-aprendizagem. Os processos educativos precisam permitir que o aluno compreenda os mecanismos da hereditariedade e aprenda os conteúdos de genética de forma significativa. Nesse sentido, a utilização de recursos tecnológicos e a realização de aulas diferenciadas das tradicionais, que usam somente quadro-giz e livro didático, podem facilitar a contextualização e aproximar os estudantes da teoria que está sendo apresentada pelo professor em sala de aula, facilitando assim o entendimento dos principais conceitos de genética (KRASILCHIK, 2004; SAVI e ULBRICHT, 2008). Miranda (2001) afirma que as atividades lúdicas complementam o conteúdo teórico permitindo maior interação entre conhecimento-professor-estudante. Entre as várias estratégias didáticas existentes que podem ser usadas estão os jogos.

O jogo educacional ou didático é aquele elaborado com o objetivo prévio de facilitar o ensino e o aprendizado do conteúdo proposto (CUNHA, 1988). De acordo com Krasilchik (2004) os jogos são metodologias pedagógicas que estimulam o aprendizado do aluno por gerar motivação e interesse em sala de aula. Dessa forma, acredita-se que é importante incorporar aos métodos tradicionais de ensino as tecnologias educacionais, tendo sempre como foco e meta a aprendizagem significativa dos alunos. Como afirma Freire (1982) a educação deve ser um ato criador, sendo os aprendentes sujeitos ativos, capazes de conhecer e interagir. Os jogos educacionais são metodologias que tornam os estudantes ativos na construção do próprio conhecimento. Os jogos representam uma forma moderna de ensinar em sala de aula, associam prazer e aprender, criam ambientes interativos e dinâmicos de ensino, motivam os estudantes com desafios e curiosidades e levam os estudantes a um estado de intensa concentração e envolvimento, potencializando o desenvolvimento de habilidades como observação, comparação, levantamento de hipóteses, argumentação, resolução de problemas, raciocínio dedutivo e memorização (VYGOTSKY, 2003; ANTUNES E SABÓIA-MORAIS, 2010).

Assim, os jogos caracterizam um recurso didático promissor para favorecer a aprendizagem significativa dos conceitos de genética. Nesse estudo, foi elaborado e aplicado em sala de aula o jogo intitulado "Jogando com a genética" visando avaliar o potencial educativo dessa tecnologia educacional.

\section{OBJETIVOS}

- Elaborar o jogo intitulado "Jogando com a Genética"

- Verificar a eficácia desse recurso didático lúdico no ensino de genética.

- $\quad$ Analisar a aceitação por parte dos estudantes da atividade realizada com o jogo.

\section{METODOLOGIA}




\section{A - Público-alvo}

O projeto teve como público-alvo adolescentes que cursavam o $3^{\circ}$ ano do Centro de Ensino em Período Integral na cidade de Cristalina, Goiás. O projeto foi desenvolvido com 31 estudantes com faixa etária entre 16 e 17 anos. Todos os estudantes aceitaram participar da pesquisa ao assinar o Termo de Consentimento Livre e Esclarecido.

\section{B - Apresentação do recurso didático}

O jogo educacional "Jogando com a Genética" foi elaborado pela professora após a avaliação dos conhecimentos prévios dos estudantes e com o objetivo de ensinar. A confecção do jogo é simples, com recursos computacionais disponíveis em muitas escolas, e pode ser facilmente reproduzida por outros professores. "Jogando com a Genética" é um jogo de perguntas e respostas, com múltiplas alternativas (material suplementar), construído por meio do programa Microsoft Office Power Point (Microsoft 2007) (Figura 1). A elaboração foi realizada por meio de slides com imagens acerca dos conteúdos e foram inseridas transições entre os slides e para a aparição das perguntas e imagens, visando tornar o jogo mais atraente. O jogo é composto por 30 perguntas com quatro opções de resposta cada e foi aplicado em sala de aula usando como ferramentas o computador e projetor multimídia. O jogo "Jogando com a Genética" pode ser jogado por dois jogadores ou por dois grupos de jogadores, sendo que esta última forma foi usada no presente trabalho visando envolver todos os estudantes nas atividades. $\mathrm{O}$ jogo foi aplicado com a mediação da professora que sempre interferiu sanando as dúvidas dos estudantes que surgiram no decorrer da partida.

O recurso didático proposto é um jogo de fases com três graus de dificuldade: a primeira fase aborda os conceitos básicos de genética; a segunda fase abordar as leis de Gregor Mendel; e a terceira e última fase abrange anomalias, sistemas sanguíneos e assuntos da atualidade que envolve a genética. Dessa forma, os conteúdos abordados no jogo são aconselhamento genético, alelos, células, centrômeros, cromatina, gene, cromossomo, DNA, anomalias, leis de Mendel, sistema sanguíneos, temas atuais da genética, entre outros.

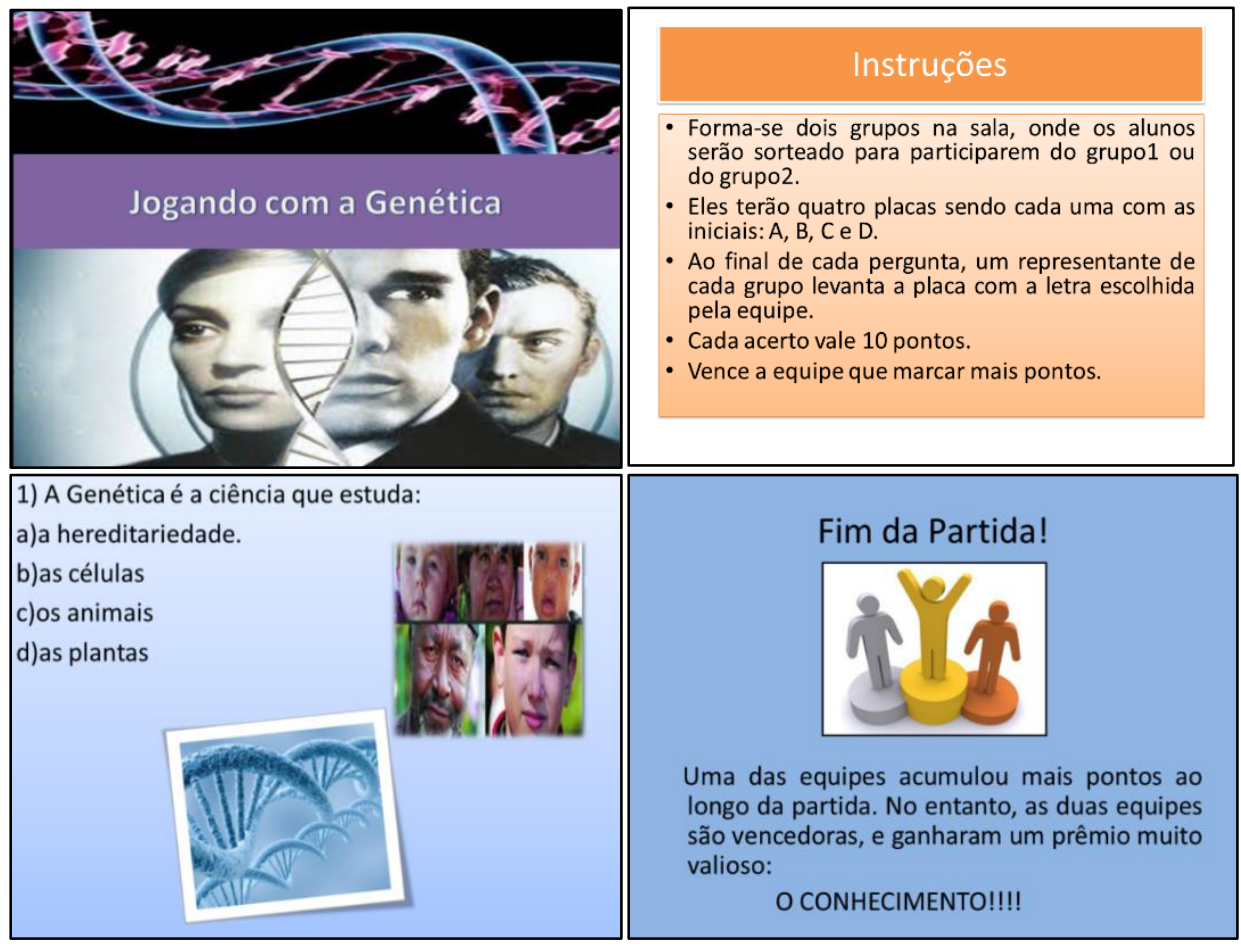

Figura 1: Imagens de alguns slides do jogo "Jogando com a Genética". 


\section{C - Desenvolvimento das atividades educativas}

O projeto foi desenvolvido em três etapas, usando quatro aulas de 50 minutos. Na primeira etapa foi apresentada a proposta do projeto, e aplicado um questionário pré-teste com o intuito de avaliar conhecimentos prévios dos alunos sobre genética. Na segunda etapa foram realizadas atividades educativas utilizando apenas o método tradicional, quadro-giz e livro didático, em que foram revisados conteúdos de genética. Em seguida foi proposto o jogo educacional como complementação do método tradicional. A terceira etapa consistiu na aplicação do questionário pósteste visando avaliar os novos conhecimentos construídos pelos estudantes.

\section{D - Avaliação}

A avaliação da proposta pedagógica foi realizada qualitativa e quantitativamente. A análise qualitativa foi feita por meio de observações das expressões orais e corporais dos estudantes durante o desenvolvimento das atividades. A análise quantitativa foi realizada por meio de dados coletados com a aplicação de questionários, como supracitado. Foi aplicado um questionário pré-teste visando avaliar conhecimentos prévios dos estudantes e estabelecer o ponto de partida para a proposta pedagógica e um questionário pós-teste visando analisar a construção do conhecimento por parte dos estudantes por meio de metodologias tradicionais somadas a atividades lúdicas. É importante ressaltar que as 12 questões dos questionários pré-teste e pós-teste referentes aos conteúdos de genética foram iguais (Tabela 1). No questionário pós-teste foram inseridas também questões para analisar satisfação dos alunos em participar da atividade lúdica realizada com o jogo (Tabela 2). A análise quantitativa deve ser considerada com cuidado devido ao baixo número amostral.

Tabela 1: Questões acerca da temática em estudo. Marcar verdadeiro ou falso para cada afirmativa. Justificar as questões falsas.

\begin{tabular}{ll}
$\begin{array}{l}\mathbf{N}^{\circ} \text { das } \\
\text { questões }\end{array}$ & Questão \\
\hline 1 & $\begin{array}{l}\text { A genética é a ciência que estuda a natureza química do material hereditário e os mecanismos de } \\
\text { transferência das informações contidas no DNA de uma geração para outra. }\end{array}$ \\
\hline
\end{tabular}

2 Gregor Mendel foi um cientista que realizou estudos sobre genética utilizando animais como cobaias e formulou a teoria da Genética Moderna.

3 O Genótipo é a constituição genética de um indivíduo que em interação com o meio ambiente determina suas características, ou seja, o seu fenótipo.

$4 \quad$ Um determinado gene é recessivo quando sua expressão só acontece em heterozigose.

5 Um indivíduo diploide homozigoto possui dois alelos diferentes e um indivíduo diploide heterozigoto possui dois alelos iguais em relação a determinada característica.

6 Os tipos sanguíneos existentes são A, B, AB e O.

7 Um surfista que se expunha muito ao sol sofreu danos em seu DNA em consequência de radiações UV, o que resultou em pequenos tumores na pele. Caso ele venha a ser pai de uma criança, ele transmitira essa doença a ela.

8 Um homem normal casa-se com uma mulher daltônica e tem uma criança normal do sexo feminino. Podemos dizer que o daltonismo não é um tipo de doença genética.

9 A interação gênica é o fenômeno em que vários genes interagem entre si para influenciar uma característica. Ela envolve graus variáveis de complexidade. Dominância incompleta, codominância, epistasia e pleiotropia são tipos de interação gênica 
A $1^{\circ}$ lei de Mendel postula que cada característica é determinada por dois fatores (alelos) que se separam na formação dos gametas e a $2^{\circ}$ lei de Mendel postula que os fatores (alelos) para cada característica segregam-se independentemente na geração de seres da mesma espécie, e que características como altura, cor da pele etc. eram transmitidas dos pais para os descendentes. Assim, um filhote diploide recebe um alelo da mãe e um alelo do pai para formar cada gene de seu genoma. tamanho dos cromossomos em cada espécie.

Tabela 2: Questões para avaliar a satisfação dos estudantes em participar do jogo.

\begin{tabular}{ll}
$\begin{array}{l}\text { No das } \\
\text { questões }\end{array}$ & \multicolumn{1}{c}{ Questão } \\
\hline $\mathbf{1}$ & $\begin{array}{l}\text { Você considera que jogar o Quiz conseguiu ajudá-lo a aprender os conteúdos da disciplina de } \\
\text { Genética? ( ) Sim ( ) Não Por que? }\end{array}$ \\
$\mathbf{2}$ & $\begin{array}{l}\text { Você considera que as tecnologias midiáticas garantem maior atratividade no contexto de ensino- } \\
\text { aprendizagem, tornando as aulas mais dinâmicas e interessantes? ( ) Sim ( ) Não Porque? }\end{array}$ \\
& $\begin{array}{l}\text { Outras disciplinas já desenvolveram atividades lúdicas semelhantes? Você acredita que elas são } \\
\text { importantes? }\end{array}$ \\
\hline
\end{tabular}

Os dados coletados com as 12 primeiras questões do questionário acerca dos conteúdos de genética foram analisadas por meio do teste estatístico não paramétrico McNemar. O objetivo desse teste estatístico foi verificar se a proposta pedagógica desenvolvida favoreceu a construção significativa de conhecimentos acerca dos conteúdos de genética. A hipótese nula (Ho) considerou que a proposta pedagógica não favoreceu a construção de conhecimentos e a hipótese alternativa $\left(\mathrm{H}_{1}\right)$ considerou que a proposta pedagógica favoreceu a construção de conhecimentos.

A estatística Qui-Quadrado aplicada no teste de McNemar permitiu comparar os dados coletados nos questionários pré e pós-teste (amostras pareadas) e avaliar se existia diferença significativa entre eles. Os dados de cada questão foram organizados em uma tabela de contingência considerando as variáveis: número de estudantes que acertaram no pré e erraram pós-teste (A), número de estudantes que acertaram no pré e acertaram no pós teste (B), número de estudantes que erraram no pré e erraram no pós teste $(C)$ e número de estudantes que erraram no pré e acertaram no pós teste (D). A eficácia do jogo educativo foi avaliada por meio do Qui-Quadrado das variáveis A e D, que indicam se houve modificação nos dados.

Assumindo que o valor crítico de qui-quadrado ( $\mathrm{X}_{2}$ ) para grau de liberdade 1e alfa $5 \%$ (probabilidade de erro de 5\%) é 3.84, X2<3.84 aceitam-se Ho e de X2>3.84 rejeita-se Ho. A análise estatística possibilitou verificar se a presente metodologia de ensino permitiu a construção significativa de novos conhecimentos. As três últimas questões do questionário que visavam avaliar a satisfação dos estudantes em participar da atividade lúdica foram analisadas de forma porcentual.

\section{RESULTADOS}

Durante a aplicação do questionário pré-teste os estudantes tiveram dificuldade em responder corretamente as questões (Gráfico 1) e também em justificar as questões falsas, muitos justificaram, porém de forma errada. Apenas 30\% dos estudantes conseguiram justificar corretamente as questões falsas, em muitos casos eles marcaram que a questão era falsa, porém, não sabiam justificar. 
Após a aplicação do questionário pré-teste foram desenvolvidas as aulas tradicionais e foi possível perceber que os estudantes tiveram muita dificuldade em aprender e relacionar os conceitos de genética quando estes conceitos estavam envolvidos em problemas. Quando foi proposto o jogo, inicialmente os estudantes ficaram um pouco tímidos e retraídos, porém eles foram motivados a mostrar o que tinham aprendido durante as aulas, e a não se preocupar com qual grupo ganharia o jogo. Para que os alunos pudessem se sentir mais motivados a participar da atividade, o jogo foi apresentado a eles da seguinte forma: "Jogando com a Genética é um jogo de perguntas e respostas para testar seu conhecimento em relação aos conceitos de Genética, em que o principal objetivo é o aprendizado de forma prazerosa e divertida". A turma foi então dividida em dois grupos para dar início à partida.

Os alunos foram muito participativos durante o desenvolvimento do jogo. Ao final de cada pergunta eles tinham um tempo para discutir a questão, trocar ideias, mostrar seu ponto de vista, e mostraram muito empenho em busca das respostas corretas. Ao final do tempo estipulado de 1 minuto para responder cada questão, a professora dizia: "já", e a placa com a resposta escolhida pelo grupo era levantada. A professora dava um clique no computador e a resposta certa era marcada na tela do jogo, nesse momento os estudantes comemoravam o acerto, se entristeciam com o erro, e em seguida acontecia à intervenção da professora. A questão era relida e feita uma análise em cada alternativa, mostrando o porquê de determinada resposta. Algumas dúvidas surgiram durante o desenvolvimento do jogo e foram esclarecidas pela professora, realizando assim dentro do jogo diversos debates. Os alunos participaram inteiramente do jogo, interagiram uns com os outros e pediram "bis". Ao final do jogo uma das equipes acumulou mais pontos. No entanto, a professora deixou claro que as duas equipes eram vencedoras, e ganharam um prêmio muito valioso: o conhecimento.

Ao final das atividades os alunos responderam ao questionário pós-teste. Houve uma diferença significativa entre o número de estudantes que acertaram cada questão no pré-teste e pós-teste (Gráfico 1 e Tabela 3). Os resultados da análise estatística permitiram confirmar que a atividade realizada com a associação entre aulas tradicionais e o jogo favoreceram a construção de novos conhecimentos e a aprendizagem significativa (Tabela 3).

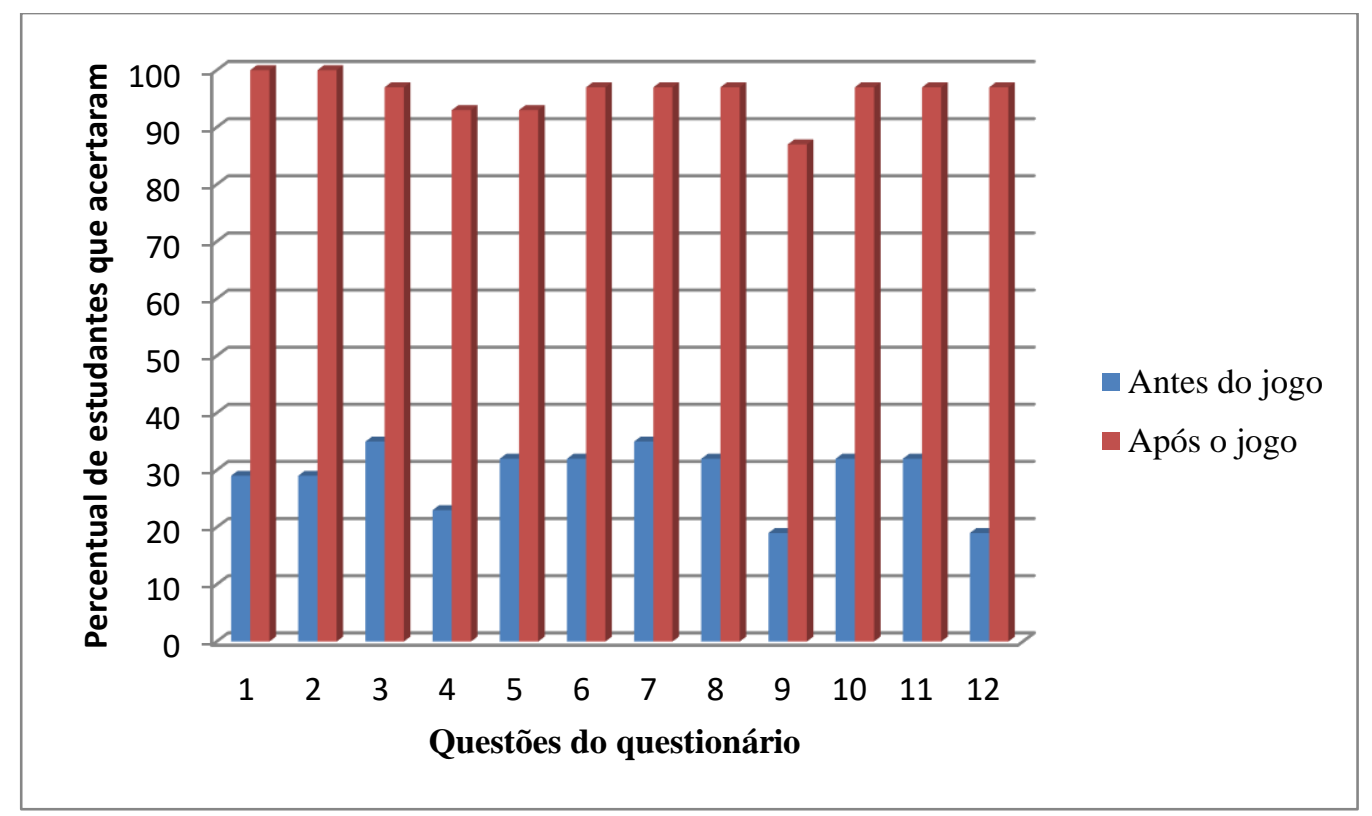

Gráfico 1: Percentual de estudantes que responderam corretamente as questões dos questionários (Numeração conforme tabela 1) antes e após o desenvolvimento da proposta pedagógica. As atividades foram realizadas com aulas tradicionais e o jogo intitulado "Jogando com a genética". 
Tabela 3: Valores de Qui-Quadrado $\left(\mathrm{x}^{2}\right)$ e $\mathrm{p}$ gerados pelo teste de McNemar para cada questão do questionário. * indica que a proposta pedagógica favoreceu a construção significativa de conhecimento para a questão.

\begin{tabular}{|c|c|c|}
\hline $\begin{array}{l}\text { Questão do } \\
\text { Questionário }\end{array}$ & $\begin{array}{c}\text { Valor de Qui- } \\
\text { Quadrado }\end{array}$ & Valor de $p$ \\
\hline $1^{*}$ & 20.04 & $<0.0001$ \\
\hline $2^{*}$ & 20.04 & $<0.0001$ \\
\hline $3^{*}$ & 15.42 & $<0.0001$ \\
\hline $4^{*}$ & 20.04 & $<0.0001$ \\
\hline $5^{*}$ & 15.42 & $<0.0001$ \\
\hline $6^{*}$ & 16.40 & $<0.0001$ \\
\hline $7^{*}$ & 15.42 & $<0.0001$ \\
\hline $8^{*}$ & 16.40 & $<0.0001$ \\
\hline $9^{*}$ & $17 \cdot 39$ & $<0.0001$ \\
\hline $10^{*}$ & 16.40 & $<0.0001$ \\
\hline $11^{*}$ & 16.40 & $<0.0001$ \\
\hline $12^{*}$ & 20.34 & $<0.0001$ \\
\hline
\end{tabular}

Foi possível perceber também que as dúvidas acerca dos conteúdos foram menores após as atividades, em relação à justificativa das questões falsas. Antes das atividades em média 30\% dos estudantes acertaram as justificativas das questões falsas. Após o desenvolvimento das atividades em média 94\% dos estudantes acertaram a justificativa das questões falsas (Tabela 4).

Tabela 4: Percentual de estudantes que acertaram a justificativa de cada questão falsa no questionário pósteste.

\begin{tabular}{cc}
\hline Questões & $\begin{array}{c}\text { Após proposta } \\
\text { pedagógica }\end{array}$ \\
\hline 2 & $91 \%$ \\
4 & $91 \%$ \\
5 & $94 \%$ \\
7 & $97 \%$ \\
8 & $97 \%$ \\
\hline
\end{tabular}

Ao final do questionário pós-teste foram acrescentadas três questões para avaliar o jogo "Jogando com a Genética" como mostra a tabela 2. Primeiro os alunos foram questionados em relação à ajuda da atividade lúdica no aprendizado da disciplina de genética, e $100 \%$ afirmaram que o jogo contribuiu para o aprendizado, esclarecendo suas dúvidas e permitindo uma maior interação entre eles e a professora:

"Estudante 1: Revendo os conteúdos e colocando em pratica os meus conhecimentos esclareço minhas dúvidas e aprendo aquilo que não tinha certeza”

"Estudante 2: Foi uma maneira mais divertida de nos entendermos o conteúdo, isso foi bacana e poderia acontecer mais vezes".

Quando questionados se as tecnologias midiáticas garantem maior atratividade no contexto de ensino-aprendizagem, tornando as aulas mais dinâmicas e interessantes, 97\% dos alunos afirmaram 
que sim, uma vez que foge da rotina, que permite que eles interajam uns com os outros, debatam e participem mais ativamente da aula. Nesse sentido alguns estudantes responderam:

"Estudante 3: Além de trazer facilidade e praticidade para as aulas, trazem mais interatividade. Ficar simplesmente preso ao livro, a aula fica chata e entediante."

"Estudante 4: Com esse método de ensino criamos um clima de competitividade, fazendo com que todos participem da aula, e aprenda um pouco mais."

"Estudante 5: Traz uma competição entre nós e estimula o estudo mais aprofundado."

"Como as tecnologias está no meio de nós aprendemos mais fácil o conteúdo de forma prazerosa e dinâmica.”

Quando questionados se outras disciplinas já desenvolveram atividades lúdicas semelhantes, $100 \%$ dos alunos disseram que não, mas acreditam que elas são importantes para o ensino aprendizado:

"Estudante 6: Acredito que sim, pois é uma forma de todos os alunos interagirem sobre a matéria explicada."

"Estudante 7: Acredito que sim, pois conseguimos compreender melhor o conteúdo e ainda possuímos uma melhor interatividade."

"Estudante 8: Acho que deveria haver mais jogos porque assim a gente iria interagir uns com os outros e ficar por dentro da disciplina."

\section{DISCUSSÃO}

$\mathrm{Na}$ presente proposta pedagógica as atividades foram iniciadas com a avaliação dos conhecimentos prévios dos estudantes. O conhecimento prévio deve ser o ponto de partida para que o professor inicie um novo conteúdo, e nesse sentido Miras (2006) e Zabala (2002) utilizam uma frase de Ausubel (1982) para enfatizar essa ideia "O fator mais importante que influi na aprendizagem é aquilo que o aluno já sabe." Pois quando se faz a investigação do conhecimento prévio acerca do conteúdo que vai ser ministrado, o professor oportuniza o aluno mostrar seus conhecimentos acerca do assunto que está em debate, fazendo com que haja uma maior interação entre aluno-professor e aluno-aluno, interação que é positiva para o processo de ensino aprendizagem. Miras (2006) afirma ainda que esse conhecimento prévio deve ser averiguado e o ensino deve depender desses dados, pois a aprendizagem acontece por meio da interação entre o conhecimento prévio e o conhecimento novo.

É muito importante detectar as dúvidas dos alunos antes de iniciar um conteúdo em sala de aula e o questionário pré-teste utilizado como ferramenta didática de avaliação na proposta pedagógica possibilitou fazer essa análise prévia. De acordo com Campos e Nigro (1999) antes de planejar as aulas, bem como as metodologias e estratégias que serão utilizadas no desenvolvimento das aulas, o professor deve fazer a investigação dos conhecimentos prévios dos alunos e se esforçar para saber quais os conhecimentos eles já possuem, pois esse deve ser o ponto de partida do planejamento. De acordo com Antunes e Sabóia-Morais (2010) os conhecimentos prévios geralmente representam um conhecimento superficial e não sistemático adquirido no cotidiano a partir de experiências de vida. Ao avaliar essas concepções prévias o professor pode propor metodologias que desafiem os conhecimentos iniciais. Segundo Carvalho (1996) a interação entre conhecimento prévio e novo permite a aprendizagem significativa e a construção e reconstrução de conceitos.

Campos e Nigro (1999) destacam que a investigação do conhecimento prévio é importante tanto para o aluno quanto para o professor. O professor descobre o que trabalhar e a melhor forma de ensinar, e elabora estratégias didáticas mais eficazes. $\mathrm{O}$ aluno tem a oportunidade de mostrar seus conhecimentos e avaliar o que sabia e o que aprendeu com o desenvolvimento das aulas. 
No desenvolvimento da proposta pedagógica, inicialmente foi utilizado um questionário em que os alunos julgaram os itens em verdadeiro ou falso e justificaram as questões falsas, uma estratégia utilizada para avaliar o conhecimento prévio e as principais dúvidas dos alunos em relação aos principais conceitos de genética. De acordo com Miras (2006) o levantamento dos conhecimentos prévios pode ser feito tanto a partir de instrumentos fechados, como listas, questionários, mapas, redes, quanto de instrumentos abertos, como conversas entre o professor e os alunos. Sendo os instrumentos fechados mais eficazes para alunos mais velhos, enquanto que as conversas costumam ser mais proveitosas para alunos mais novos. O professor deve estar atento a essa questão e se adequar a melhor estratégia para a análise dos conhecimentos prévios acerca dos conteúdos. Na presente proposta optou-se pelo uso dos questionários devido ao perfil da turma, que era de estudantes que cursavam a série final do Ensino Médio, e que conseguiram expressar bem os seus conhecimentos nos questionários.

Nesse estudo, a proposta pedagógica com o jogo "Jogando com a genética" foi elaborada considerando os conhecimentos prévios dos estudantes bem como a essência das metodologias lúdicas. $\mathrm{O}$ uso do jogo no ensino de genética representou uma forma diferenciada e moderna de ensinar em sala aula, ao associar aulas tradicionais e tecnologias educacionais. De acordo com Antunes e Sabóia-Morais (2010) as metodologias diferenciadas de ensino aprendizagem facilitam o entendimento do aluno de conteúdos complexos e favorecem a socialização do conhecimento. Em meio às metodologias diferenciadas que podem ser usadas em sala de aula estão aquelas de caráter lúdico que motivam os alunos e estimulam a aprendizagem de forma prazerosa (NASCIMENTO et al 2015; MASCARENHAS et al 2016; FERREIRA et al 2016). O lúdico é importante em todas as faixas de idade, e deve ser trabalhado com o intuito de diversificar e complementar o ensino tradicional, não sendo vistos apenas como diversão em sala de aula, mas sim uma metodologia que estimule a participação do aluno e desperte o interesse pelo conteúdo ministrado, principalmente se for um conteúdo de difícil entendimento, como é o caso da genética.

Os jogos educativos podem aumentar a motivação e a criatividade, beneficiar o desenvolvimento cognitivo e facilitar a aprendizagem. Essa tecnologia educacional lúdica permite uma maior interação e participação dos alunos, uma vez que eles são oportunizados a debater e mostrar sua opinião em relação ao conteúdo ministrado (ANTUNES e SABÓIA-MORAIS, 2010).

Há muito tempo se vem trabalhando em busca de melhorar a qualidade de ensino e as formas de ensinar, em que o aluno não seja visto como um banco de informações, e sim como parte fundamental do ensino, em que ele seja solidário e autônomo, capaz de compreender e mostrar seu conhecimento. As novas tecnologias associadas ao método tradicional podem tornar o aluno mais ativo nos processos educativos. Nesse sentido, Freire (1982, p. 78) afirma que:

O educador já não é o que apenas educa, mas o que, enquanto educa, é educado, em diálogo com o educando que, ao ser educado, também educa.

Freire (1975) denominava o modelo tradicional de prática pedagógica, em que o professor era detentor do conhecimento e o aluno o receptor onde o conhecimento era depositado, de "educação bancária". Mas as atuais tendências pedagógicas vêm rompendo com as práticas tradicionais e com isso os papéis do professor, do aluno e da escola são modificados. Nesse contexto o professor assume o papel de mediador do processo de ensino aprendizagem, mediando o caminho entre o aluno e o novo conhecimento, buscando uma maior participação e interação dos alunos, sendo inovador, e estimulando os estudantes na busca de soluções para seus conflitos cognitivos. O aluno passa a ser ativo no processo de construção de novos saberes e a escola assume o papel de formar cidadãos críticos, reflexivos, capazes de gerar mudanças significativas na sociedade. Freire denominava essa nova tendência de educação como problematizadora, e destacava a importância da troca mútua de conhecimentos entre educando e educador, e afirmava que ambos devem interagir e que um deve aprender com o outro, e não apenas o professor transmitir conhecimento e o aluno receber. 
As atividades realizadas na presente proposta lúdica foram conduzidas de acordo com as novas tendências pedagógica. Durante a realização do jogo "Jogando com a Genética" os alunos participaram ativamente gerando um debate em torno do assunto discutido. Houve muita interação entre os estudantes e dos estudantes com a professora, assim os alunos mostraram autonomia e capacidade de interpretar o que lhe foi proposto. Dessa forma a aprendizagem significativa pode ser favorecida com o uso de novos recursos metodológicos que atraiam os alunos, que tornem a aula prazerosa e dinâmica e os estudantes participem ativamente, não sendo apenas um banco onde o conhecimento é depositado sem questionamento e discussão. No presente estudo foi possível verificar que a associação entre aulas tradicionais e jogos permitiu a construção significativa de conhecimentos por parte dos estudantes. O uso de tecnologias educacionais em sala de aula favoreceu o processo de ensino aprendizagem.

O ensino de genética por meio de metodologias lúdicas é encontrado em vários trabalhos na literatura em que os educadores aplicaram e avaliaram jogos educacionais. Martinez et al (2008) justificam a importância de metodologias diferenciadas ao afirmar que no ensino de genética são necessárias atividades práticas que auxiliem os alunos no aprendizado dos conceitos teóricos e, dessa forma, esse autor propõe a utilização de jogos com o objetivo de promover a difusão e popularização da ciência de forma criativa, lúdica e interativa. Martinez et al (2008) elaboraram um jogo de perguntas e respostas intitulado "Show da Genética" com diversos conceitos dessa disciplina, visando estimular os alunos e professores a jogar, debater e aprender de forma prazerosa. Para os professores e alunos foi uma experiência enriquecedora, claramente visível pela participação e alegria de jogar, resposta esta obtida por meio de um questionário aplicado ao final da atividade. Desta forma, os resultados do trabalho de Martinez et al (2008) indicaram que o jogo "Show da Genética" complementou os conceitos teóricos e facilitou o processo de ensino-aprendizagem de Genética. Silva et al (2009) criaram e aplicaram o "Quiz de Genética e Biologia Molecular", ressaltaram que os alunos aprenderam os conteúdos de forma divertida e interativa.

Freitas et al (2011) também ressaltaram em seu trabalho a importância de metodologias diferenciadas e afirmaram que a genética é recorrentemente referida pelo fato de abordar conteúdos científicos caracterizados por um vasto e complexo vocabulário que dificulta a compreensão e a diferenciação dos conceitos envolvidos, como é o caso dos associados a termos como alelos, gene ou homólogo. Para facilitar o processo de ensino aprendizagem de genética esses autores elaboraram e aplicaram um jogo de queimada. O jogo baseia-se num conhecido jogo infantil chamado queimada, que pode ser jogado por dez jogadores e um orientador, que coordena as atividades. No decorrer do jogo, os jogadores entraram em contato direto com diversos assuntos como a estrutura do DNA, transcrição, tradução, primeira lei de Mendel e demais temas de Genética. Esse jogo promoveu a interação dos alunos, estimulando-os a competir e aprender ao mesmo tempo, sendo assim uma complementação para o ensino tradicional. Dessa forma, os resultados do trabalho de Freitas et al (2011) mostraram que o jogo da queimada foi um recurso facilitador, auxiliando os professores e estudantes no entendimento dos conceitos básicos de Genética. Além disso, o jogo despertou o interesse dos estudantes pela ciência, em particular pela Genética.

Segundo Lara (2004) os jogos vêm ganhando espaço na sala de aula porque os professores estão buscando uma forma de tornar o ensino algo mais fascinante, mais prazeroso e diversificado. $\mathrm{O}$ uso de jogos na educação deve ser valorizado, pois permite a mudança no papel do professor no contexto da aprendizagem e do aluno na participação e interação. Essas novas tecnologias educacionais permitem ao professor atuar como condutor e estimulador, exercendo o papel fundamental de guiar a construção de significados pelos estudantes.

Entende-se aqui o conceito de jogo didático como um objeto ou recurso de ensino com o objetivo de proporcionar determinadas aprendizagens, com propriedades lúdicas. Assim, o jogo traz este diferencial do estímulo, transformando a ação educadora em uma experiência que contempla os aspectos social e pessoal, sendo 
usado como um recurso importante na aproximação dos alunos ao conhecimento específico, aumentando seu desempenho inclusive em conteúdos tidos como de difícil assimilação (Oliveira, Junior e Schimiguel 2012, p.2).

Considerando os resultados positivos das metodologias lúdicas no ensino de genética encontrados na literatura e comprovados com o jogo "Jogando com a genética" acredita-se que os jogos podem ser utilizados em sala de aula como complementação à metodologia tradicional, favorecendo a construção de novos conhecimentos de forma prazerosa e interessante. Nesse estudo, ao final do jogo os estudantes estavam aptos a definir, interpretar e analisar os principais conceitos de genética, associando-os ao seu dia-a-dia.

\section{CONCLUSÃO}

Os resultados obtidos na presente pesquisa indicam que as tecnologias lúdicas incorporadas aos métodos tradicionais de ensino possibilitam a motivação dos estudantes e maximiza a interação entre estudantes e professores, permitindo assim os professores atuarem como mediadores do processo de ensino aprendizagem e os estudantes serem ativos na construção de novos saberes. $\mathrm{O}$ uso do jogo como tecnologia educacional complementar as aulas tradicionais permitiu a construção estatisticamente significativa de novos conhecimentos de genética pelos estudantes. Além disso, o uso do jogo educacional como recurso lúdico em sala de aula teve uma boa aceitação por parte dos estudantes. Essa pesquisa foi relevante porque a comprovação da eficácia do jogo "Jogando com genética" pode caracterizá-lo como positivo em proposta de ensino de genética, o que permitirá a sua reprodução e utilização por outros educadores que atuam no ensino básico ou superior.

\section{REFERENCIAS}

ANTUNES, A.M.; SABÓIA-MORAIS, S.M.T. O jogo Educação e Saúde: uma proposta de mediação pedagógica no ensino de Ciências. Experiências em Ensino de Ciências, v.5, n.2, p. 55-70, 2010.

AUSUBEL, D.P. A aprendizagem significativa: a teoria de David Ausubel. São Paulo: Moraes, p.112, 1982.

AUSUBEL, D.P.; NOVAK, J.D. e HANESIAN, H. Psicologia cognitiva. Tradução de: Eva Nick, $2^{a}$ ed. Rio de Janeiro: Editora Interamericana, p.623, 1980.

CAMPOS, M.C.C.; NIGRO, R.G. Aquilo que os alunos já sabem. In: Didática de ciências: o ensinoaprendizagem como investigação. São Paulo: FTD, p.78-97, 1999.

CARVALHO, A. M. P. Referenciais teóricos para análise do processo de Ensino de Ciências. Caderno de pesquisa, São Paulo, n. 96, 1996.

CUNHA, N. Brinquedos, desafio e descoberta. Rio de Janeiro: FAE. 1988.

FERREIRA, M.M.; ALMEIDA, M.C.C.; OLIVEIRA, L.J.; ANJOS, H.A.; NASCIMENTO, L.M.M. Tabuleiro Humano: Uma Forma Inovadora de Ensinar Botânica no Ensino Médio. Agroforestalis News, v.1, n.1, p.25-30, 2016.

FREIRE, P. Pedagogia do oprimido. Rio de Janeiro, Ed. Paz e Terra, 2ª edição, p 44, 1975.

FREIRE, P. A importância do ato de ler. São Paulo: Cortez, p.104, 1982.

FREITAS, R. P.; Souza, K.F.C.S; Oliveira, M.R.; Costa, A.G.; Santos, J.D.; Alecrim, P.H.; Conceição, J.K.T.; Ovellar, M.I. Jogo da queimada: Uma pratica para o Ensino de Genética. Genética na escola, v.6, n. 2, p. 46-53, 2011.

KRASILCHIK M. Prática de Ensino de Biologia. $4^{\circ}$ Ed., São Paulo: Editora da Universidade de São Paulo, p.197, 2004. 
LARA, I.C.M. Jogando com a Matemática de 5ª a 8aㅗ série. São Paulo: Rêspel, p.170, 2004.

MARTINEZ, E. R. M. et al Show da Genética: um jogo interativo para o ensino de Genética. Genética na escola, v.3, n. 1, p. 1-3, 2008.

MASCARENHAS, M.J.O; SILVA, V.C.; MARTINS, P.R.P; FRAGA, E.C.; BARROS, M.C. Estratégias Metodológicas para o Ensino de Genética em Escola Pública. Pesquisa em Foco, v. 21, n.2, p.05-24. 2016.

MIRANDA S. No fascínio do jogo, a alegria de aprender. Ciência Hoje, v.28, n.168, p.64-66, 2001.

MIRAS, M. O ponto de partida para a aprendizagem de novos conteúdos: os conhecimentos prévios. In: COLL, C. O construtivismo em sala de aula. São Paulo: Editora Ática, 20o6. p.57- 76

MOREIRA, M. C. A.; SILVA, E. P. Concepções prévias: uma revisão de alguns resultados sobre genética e evolução. In: Evento Regional de Ensino de Biologia. Niterói, 2001, Anais.

NASCIMENTO, M.P.; CRUZ, A.H.S.; SANTOS, R.S.; CINTRA, L.C. Jogos Lúdicos como ferramenta didática para o Ensino de Genética e Biologia Molecular. Revista Eletrônica de Educação da Faculdade Araguaia, v.7, p.250-271, 2015 .

OLIVEIRA, L.P, JUNIOR, H.R e SCHIMIGUEL, J. Ensino de matemática financeira com jogo interativo entre equipes: Um estudo de caso. Experiências em Ensino de Ciências, v.7, n.3, p.2-4, 2012.

SAVI, R.; ULBRICHT, V. R. Jogos digitais educacionais: benefícios e desafios. Revista Novas Tecnologias na Educação. v.6, n. 2, p 2-10, 2008.

SILVA, J.M.A.; CANEDO, R.V.; ABRANTE, T.A.S.; SOUZA, R.A.; UTAGAWA, C.Y. Quiz de Genética e Biologia Molecular - A experiência discente e docente no desenvolvimento de um material didático. Cadernos UniFOA, n.11, p.65-68, 2009 .

TRIVELATO, S. L. F. Ensino de genética: Um ponto de Vista. São Paulo, Faculdade de Educação, p.86, 1988.

VYGOTSKY, L.S. Psicologia pedagógica. Trad.Claudia Schilling. Porto Alegre: Artmed, p.576, 2003.

ZABALA, A. Enfoque globalizador e pensamento complexo: uma proposta para o currículo escolar. Porto Alegre: Artmed, p.248, 2002.

Meiridiane Ribeiro da Silva: Possui graduação em Ciências Biológicas, modalidade Licenciatura. É Especialista em Tecnologias Aplicadas ao Ensino de Biologia pela Universidade Federal de Goiás. Professora no ensino básico.

E-mail: meiridianeribeirodasilva@yahoo.com.br

Adriana Maria Antunes: Possui graduação em Ciências Biológicas, modalidade Licenciatura, mestrado em Biologia, modalidade Biologia Celular e Molecular, e doutorado em Genética e Biologia molecular, todos pela Universidade Federal de Goiás (UFG). Possui experiência nas áreas de Biologia Celular, Histologia, Genética, Genômica, Metagenômica e Bioinformática. Atualmente é bolsista de Pós-doutorado no Programa Nacional de Pós Doutorado da CAPES (PNPD) e realiza atividades nas linhas de pesquisa Genética e Genômica de plantas do Cerrado e Metagenômica Ambiental.

E-mail: adrianaantunesbio@gmail.com 